\title{
Serotonergic Neurons Activate Chemosensitive Retrotrapezoid Nucleus Neurons by a pH-Independent Mechanism
}

\author{
Daniel K. Mulkey, ${ }^{1}$ Diane L. Rosin, ${ }^{1}$ Gavin West, ${ }^{1}$ Ana C. Takakura,,${ }^{1,2}$ Thiago S. Moreira,,${ }^{1,2}$ Douglas A. Bayliss, ${ }^{1}$ and \\ Patrice G. Guyenet ${ }^{1}$ \\ ${ }^{1}$ Department of Pharmacology, University of Virginia, Charlottesville, Virginia 22908, and ²Department of Physiology, Universidade Federal de São Paulo, \\ Escola Paulista de Medicina, São Paulo, SP 04023-060, Brazil
}

\begin{abstract}
Serotonin activates respiration and enhances the stimulatory effect of $\mathrm{CO}_{2}$ on breathing. The present study tests whether the mechanism involves the retrotrapezoid nucleus (RTN), a group of medullary glutamatergic neurons activated by extracellular brain pH and presumed to regulate breathing. We show that the RTN is innervated by both medullary and pontine raphe and receives inputs from thyrotropin-releasing hormone (TRH) and substance P-expressing neurons. Coexistence of serotonin and substance P in terminals within RTN confirmed that lower medullary serotonergic neurons innervate RTN. In vivo, unilateral injection of serotonin into RTN stimulated inspiratory motor activity, and pH-sensitive RTN neurons were activated by iontophoretic application of serotonin or substance P. In brain slices, pH-sensitive RTN neurons were activated by serotonin, substance P, and TRH. The effect of serotonin in slices was ketanserin sensitive and persisted in the presence of glutamate, GABA, glycine, and purinergic ionotropic receptor antagonists. Serotonin and $\mathrm{pH}$ had approximately additive effects on the discharge rate of RTN neurons, both in slices and in vivo. In slices, serotonin produced an inward current with little effect on conductance and had no effect on the pH-induced current. We conclude that (1) RTN receives input from multiple raphe nuclei, (2) serotonin, substance $\mathrm{P}$, and TRH activate RTN chemoreceptors, and (3) excitatory effects of serotonin and $\mathrm{pH}$ are mediated by distinct ionic conductances. Thus, RTN neurons presumably contribute to the respiratory stimulation caused by serotonergic neurons, but serotonin seems without effect on the cellular mechanism by which RTN neurons detect pH.
\end{abstract}

Key words: chemosensitivity; raphe; central respiratory control; ventral medullary surface; $\mathrm{pH}$ signaling; brain slice

\section{Introduction}

Serotonergic neurons, in particular those located in the medulla oblongata, activate breathing and enhance the global response of the respiratory network to CNS acidification, the process known as the central chemoreflex (Hodges et al., 2004a,b; Taylor et al., 2005, 2006; Li et al., 2006). Conversely, transgenic mice in which serotonergic neurons do not develop (Lmx1b knock-out mice) or rats with selective lesions of raphe magnus serotonergic neurons have an attenuated central chemoreflex in adulthood (Dias et al., 2007; Hodges et al., 2007). Various mechanisms have been proposed to account for these effects, including that serotonergic neurons have a globally excitatory effect on the breathing network and are intrinsically chemosensitive, i.e., directly activated by CNS acidification (Bradley et al., 2002; Severson et al., 2003; Richerson, 2004).

Received Sept. 11, 2007; revised Nov. 10, 2007; accepted Nov. 10, 2007.

This work was supported by National Institutes of Health Grants F32 HL80890 (D.K.M.), HL28785 and HL074011 (P.G.G.), and NS33583 (D.A.B.), as well as Coordenação de Aperfeiçoamento de Pessoal de Nível Superior Grants BEX3495/04-3 (T.S.M.) and BEX 4402/05-7 (A.C.T.).

Correspondence should be addressed to Daniel K. Mulkey, Department of Physiology and Neurobiology, University of Connecticut, 75 North Eagleville Road, Unit 3156, Storrs-Mansfield, CT 06269-9011. E-mail: daniel.mulkey@uconn.edu.

DOI:10.1523/JNEUROSCI.4167-07.2007

Copyright $\odot 2007$ Society for Neuroscience $\quad$ 0270-6474/07/2714128-11\$15.00/0
Subsets of presumed serotonergic neurons are indeed activated by $\mathrm{CO}_{2}$ in vivo, but many are unresponsive to this stimulus (Veasey et al., 1995; Mulkey et al., 2004), suggesting that other mechanisms are likely to contribute to the enhancement of breathing and of the central chemoreflex by serotonergic neurons. Because serotonergic neurons collectively innervate all the brain regions that are essential to breathing (Lindsay and Feldman, 1993; Bonham, 1995; Schwarzacher et al., 2002; Manzke et al., 2003; Richter et al., 2003), many other mechanisms in addition to their putative intrinsic response to acidification could account for the role of these neurons in the chemoreflex.

Here we consider the possibility that serotonergic neurons might activate respiration at rest and affect its control by $\mathrm{CO}_{2}$ by stimulating the retrotrapezoid nucleus (RTN), a group of highly chemosensitive medulla oblongata neurons that are assumed to drive the breathing network (Nattie et al., 1993; Guyenet et al., 2005; Rosin et al., 2006; Takakura et al., 2006). This hypothesis rests on prior evidence for potentiative interactions between the caudal medullary raphe and RTN on respiratory drive and the chemoreflex ( Li et al., 2006) and is also supported by the fact that injection of raphe neuron transmitters such as substance $\mathrm{P}$ and thyrotropin-releasing hormone (TRH) into the RTN region activates breathing (Chen et al., 1990b; Cream et al., 1999). The 
present study is therefore designed to test the effect of serotonin and other raphe transmitters on single RTN neurons and to determine whether serotonin modifies the cellular mechanism responsible for the $\mathrm{pH}$-sensitivity of these neurons. First, we determined whether serotonin neurons innervate RTN and identified the probable source of those serotonergic afferents. Second, we explored whether these transmitters activate RTN neurons when applied in vivo in the vicinity of these neurons. Finally we explored the cellular mechanism of action of serotonin on RTN neurons in slices and compared it to the effect of acidification on the same cells.

We find an extensive serotonergic projection to the RTN that likely derives from multiple raphe nuclei, and we show that raphe transmitters increase RTN discharge both in vivo and in vitro; these excitatory effects are independent of the $\mathrm{pH}$-sensing mechanism. These results support the hypothesis that serotonergic neurons can activate respiration and central chemosensitivity by stimulating RTN chemoreceptors.

\section{Materials and Methods}

Whole-animal physiology and anatomical experiments were performed on adult male Sprague Dawley rats (250-350 g; Taconic, Germantown, NY). Slice work was performed on 7- to 10-d-old Sprague Dawley rats of either sex. The work was conducted in accordance with National Institutes of Health and Institutional Animal Care and Use guidelines, and the Animal Research Committee of the University of Virginia approved all procedures and protocols.

Retrograde tracing. Rats were deeply anesthetized with a mixture of ketamine $(75 \mathrm{mg} / \mathrm{kg})$, xylazine $(5 \mathrm{mg} / \mathrm{kg})$, and acepromazine $(1 \mathrm{mg} / \mathrm{kg}$, i.m.). A small skin incision was made to reveal the mandibular branch of the facial nerve on one side, and a stimulation electrode was inserted in the fascia next to it. A unilateral craniotomy was made in the occipital plate to allow electrode insertion. Cholera toxin subunit B (CTB; $1 \%$ in $0.2 \mathrm{M}$ phosphate buffer, $\mathrm{pH}$ 7.35; List Biological Laboratories, Campbell, CA) was injected into RTN by iontophoresis $(+2 \mu \mathrm{A}, 5 \mathrm{~s}$ on $5 \mathrm{~s}$ off for 10 min) using glass pipettes pulled to a $\sim 5 \mu \mathrm{m}$ tip (external diameter). Antidromic field potentials elicited in the facial motor nucleus were recorded through the injection pipette to place its tip correctly in RTN, i.e., $200-300 \mu \mathrm{m}$ below the caudal and medial edge of the facial motor nucleus (Chen et al., 1990b; Mulkey et al., 2004; Rosin et al., 2006). After surgery, the rats were treated with an antibiotic (ampicillin, $100 \mathrm{mg} / \mathrm{kg}$, i.m; American Pharmaceutical Partners, Schaumberg, IL) and an analgesic (ketorolac tromethamine, $0.6 \mathrm{mg} / \mathrm{kg}$, s.c.; Abbott Laboratories, North Chicago, IL).

Histology. Brain tissue was obtained from eight CTB-injected rats (6-12 d after tracer injection) and 10 uninjected rats that had been deeply anesthetized with pentobarbital and perfused transcardially with $100 \mathrm{ml}$ of PBS followed by $500 \mathrm{ml}$ of $4 \%$ paraformaldehyde in $100 \mathrm{~mm}$ phosphate buffer. After postfixation in the same fixative for $24-48 \mathrm{~h}$, series of coronal sections $(30 \mu \mathrm{m})$ were cut using a vibrating microtome and stored in cryoprotectant solution at $-20^{\circ} \mathrm{C}$ for up to 2 weeks as described previously (Rosin et al., 2006). Sections were incubated free-floating in primary antibodies in $0.1 \mathrm{~m}$ Tris-buffered saline, $\mathrm{pH} 7.4$, with $10 \%$ horse serum and $0.1 \%$ Triton $\mathrm{X}-100$ for $24 \mathrm{~h}$ at $4^{\circ} \mathrm{C}$ unless otherwise noted. CTB was detected using a rabbit antibody (1:1000, $48 \mathrm{~h}$ incubation; Sigma-Aldrich, St. Louis, MO; \#C3062) followed by a Cy3-tagged donkey anti-rabbit IgG (1:200; Jackson ImmunoResearch, West Grove, PA); this rabbit anti-CTB antibody gives the same pattern of labeling as a goat anti-CTB (List Biological Laboratories, \#703) whose specificity we have previously confirmed (Rosin et al., 2006). In some cases, CTB (1:20,000) was detected by tyramide amplification as described previously (Stornetta et al., 2006). Serotonin terminals were identified with an antibody directed against serotonin, which gave a more robust labeling of terminals than antibodies directed against tryptophan hydroxylase or the serotonin transporter. Serotonin was detected with a rat monoclonal antibody $(1: 100 ; 48-72 \mathrm{~h}$ incubation in $10 \%$ horse serum $/ 0.3 \%$ Triton; Millipore, Billerica, MA; \#MAB352, clone YC5/45) followed by either
Cy3-tagged donkey anti-rat IgG (1:200; Jackson ImmunoResearch) or Alexa488-tagged donkey anti-rat IgG (1:200; Invitrogen, Carlsbad, CA). Serotonergic cell bodies were identified with a mouse monoclonal antibody against tryptophan hydroxylase (TrpH; 1:1000; Sigma; \#T0678, clone WH-3) followed by an Alexa488-tagged goat-anti-mouse IgG3 (1: 200; Invitrogen). Phox $2 \mathrm{~b}$ immunoreactivity was detected in combination with substance P receptor [neurokinin-1 receptor (NK1R)] immunoreactivity using two rabbit antibodies in a sequential method as described previously (Rosin et al., 1993). First, Phox2b was identified in cell nuclei using a rabbit antibody [1:800, generously provided by J. F. Brunet, École Normale Supérieure, Paris, France (Pattyn et al., 1997); $24 \mathrm{~h}$ incubation in buffer with $0.5 \%$ TNB (a casein-blocking reagent, Tyramide Signal Amplification kit, Perkin-Elmer, Boston, MA) and $0.3 \%$ Triton X-100] followed by biotinylated donkey anti-rabbit (1:500; Jackson ImmunoResearch) and avidin-biotin reagents (Vectastain Elite Kit, Vector Laboratories, Burlingame, CA) and detection with nickel DAB (nickel ammonium sulfate/3, $3^{\prime}$-diaminobenzidine) to produce a blue-black product. Second, NK1R was detected with a rabbit antibody (1:5000, Millipore, \#AB5060; incubation for $48 \mathrm{~h}$ in buffer with $0.5 \%$ TNB and $0.3 \%$ Triton X-100) followed by biotinylated donkey antirabbit (1:500; Jackson ImmunoResearch) and avidin-biotin reagents but reacting optimally with $\mathrm{DAB}$ to produce a light brown product.

Terminals containing TRH were identified with a rabbit antibody (1: 100, Biogenesis, Poole, UK; distributed in the United States by Accurate Chemical \& Scientific, Westbury, NY; \#ICC PTR). Substance $\mathrm{P}$-containing nerve terminals were identified alone with rat antisubstance P (Millipore \#MAB356) or in combination with the tryptophan hydroxylase detection protocol using Cy3-tagged donkey anti-rat IgG (1:200; Jackson ImmunoResearch) and Alexa488-tagged goat antimouse IgG3 (1:200; Invitrogen), respectively, to test for colocalization of these substances in nerves terminals within RTN. In other experiments, substance P [detected with Alexa488-tagged donkey anti-rat IgG (1:200; Invitrogen)] and phenyl-ethanolamine $\mathrm{N}$-methyl transferase (PNMT) were simultaneously identified to test for the presence of the peptide in terminals of the $\mathrm{C} 1$ adrenergic neurons that innervate RTN. In such cases, PNMT was identified using a rabbit antibody (1:3000; generously provided by M. Bohn, Northwestern University Medical School, Chicago, IL) (Bohn et al., 1987) followed by Cy3-tagged donkey anti-rabbit $\operatorname{IgG}$ (1:200; Jackson ImmunoResearch) (Rosin et al., 2006).

The antibodies against CTB, serotonin, tryptophan hydroxylase, PNMT, substance $\mathrm{P}$, and Phox $2 \mathrm{~b}$ have been used previously, and their specificity has been established in rat brain in previous studies in our laboratory (Rosin et al., 2006; Stornetta et al., 2006). Labeling with the commercially available rabbit anti-NK1R matches the distribution of the receptor that we have observed previously with a guinea pig anti-NK1R from the same company (Wang et al., 2001) and that reported previously with a well characterized rabbit anti-NK1R (Nakaya et al., 1994). In addition, there was no NK1R immunoreactivity when NK1R-expressing cells in the ventral respiratory column were selectively destroyed by the saporin toxin conjugated with an NK1R agonist (SSP-SAP) (Wang et al., 2001). The rabbit anti-TRH antibody was directed against hemocyaninconjugated TRH; preabsorption of the TRH antibody with a threefold molar excess of the TRH peptide resulted in a complete lack of immunolabeling (data not shown).

Brainstem sections were mounted in sequential order on slides and examined using a conventional multifunction Zeiss (Oberkochen, Germany) Axioskop 2 microscope. A reference section was selected in each brain corresponding to the most caudal aspect of the facial nucleus and was assigned the level $11.6 \mathrm{~mm}$ caudal to bregma according to the atlas of Paxinos and Watson (2005). Sequential levels in sections rostral or caudal to the reference section were calculated by using the known interval $(180 \mu \mathrm{m})$ between consecutive sections (see Fig. 3, left column) or by the presence of expected landmarks identified under dark-field illumination (see Fig. 3, right column, dorsal landmarks). Computer-assisted drawings of CTB injection sites and maps of retrogradely labeled neurons were constructed with the Neurolucida software (MicroBrightField, Williston, VT) using a Ludl motor driven microscope stage and the Lucivid camera as previously described (Guyenet et al., 2002; Rosin et al., 2003). The Neurolucida files were exported to NeuroExplorer (MicroBright- 

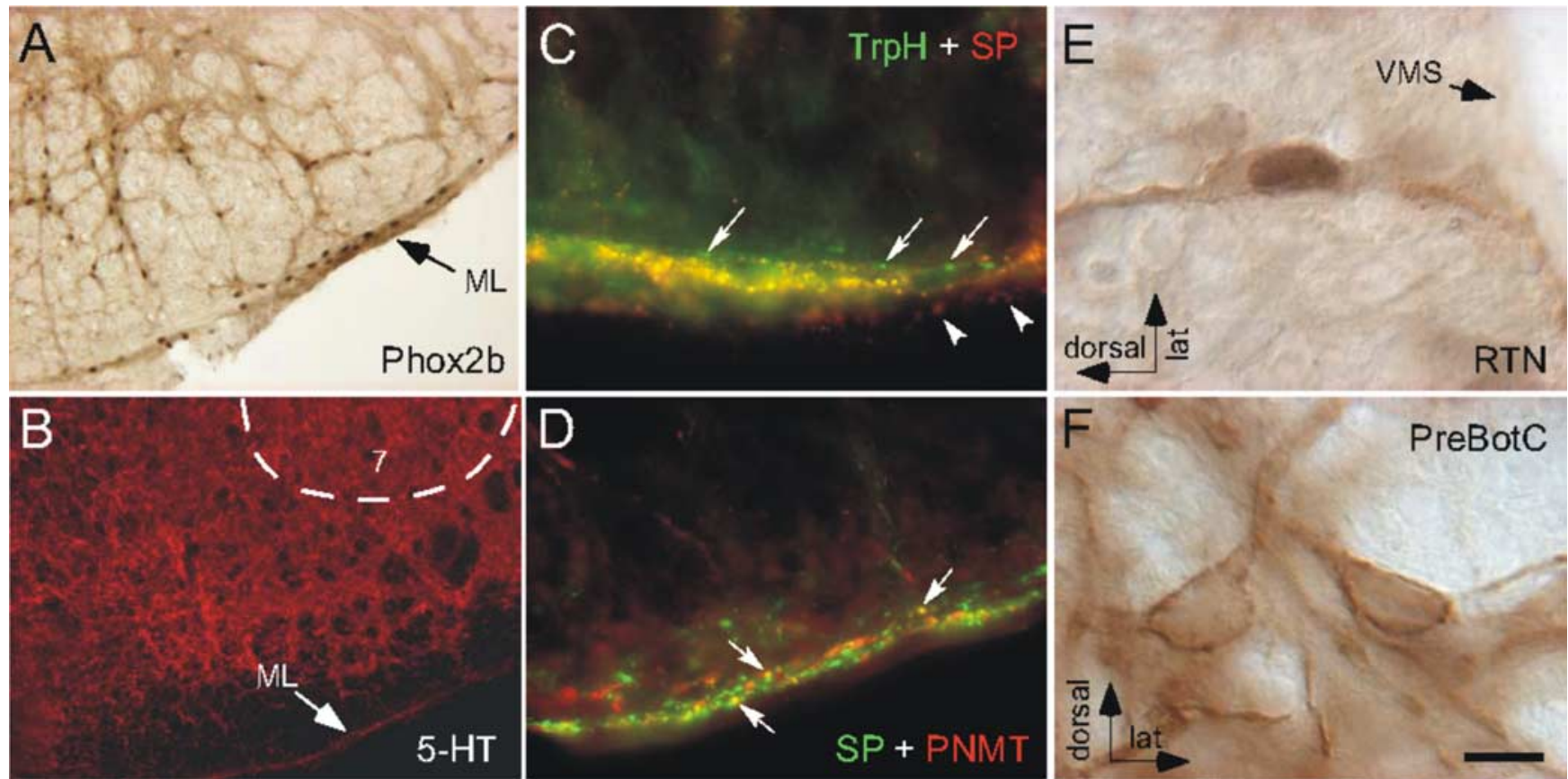

Figure 1. Serotonergic innervation of the RTN. $A$, Anatomical definition of RTN. Neuronal nuclei are immunoreactive for Phox2b. A portion of the Phox2b-ir chemoreceptors are located within the marginal layer of the ventral medulla (ML), and the rest are in a more dorsal location (the dorsal cap of RTN). A small fraction of the Phox2b-ir cells of the dorsal cap are not chemoreceptors but are adrenergic neurons (Stornetta et al., 2006). B, 5-HT-immunoreactive terminals within the RTN region ventromedial to facial nucleus (7), including the ML. The serotonin-poor region dorsal to the ML corresponds to the spinocerebellar tract. C, Many of the TrpH-ir terminals (Alexa 488, green) located within the marginal layer of RTN contain substance P (SP; Cy3, red) and appear yellow on the figure. Single-labeled terminals containing only TrpH (arrows) or SP immunoreactivity (arrowheads; different plane of focus) can be seen at the dorsal and ventral edges of the ML, respectively. $\boldsymbol{D}$, Only a few SP-ir terminals (Alexa 488, green) located within the marginal layer of RTN contain PNMT (Cy3, red) and appear yellow (arrows). $\boldsymbol{E}$, Example of one RTN neuron, identified by the presence of a Phox2b-ir nucleus and its location close to the ventral medullary surface (VMS), that contains NK1R immunoreactivity. $\boldsymbol{F}$, Two neurons of the pre-Bötzinger complex (PreBötC) containing high levels of NK1R immunoreactivity but no Phox2b. Scale bar: (in $\boldsymbol{F}) \boldsymbol{A}, 100 \mu \mathrm{m} ; \boldsymbol{B}, 134 \mu \mathrm{m} ; \boldsymbol{C}, \boldsymbol{D}, 21.4 \mu \mathrm{m} ; \boldsymbol{E}, \boldsymbol{F}, 10 \mu \mathrm{m}$.

Field) to count cells within a defined area and into the Canvas drawing software (Version 9, Deneba Systems, Miami, FL) for text labeling and final presentation. Neuroanatomical nomenclature used here is based on that defined by Paxinos and Watson (2005), and subdivisions of the ventral respiratory column are as defined previously (Alheid et al., 2002). Photographs were taken with a 12 bit color CCD camera (Retiga 1300, resolution $1392 \times 1042$ pixels; QImaging, Burnaby, British Columbia, Canada). Digital photographs were saved as TIFF files and imported into Adobe Photoshop (version 7; Adobe Systems, Mountain View, CA) and Canvas to label and assemble figures.

Neurophysiological experiments in vivo. These experiments were done in bilaterally vagotomized, artificially ventilated rats anesthetized with urethane and prepared as previously described (Takakura et al., 2006). Briefly, general anesthesia was induced with $5 \%$ halothane in $100 \% \mathrm{O}_{2}$. Artificial ventilation with $1.4-1.5 \%$ halothane in $100 \% \mathrm{O}_{2}$ was maintained throughout surgery. The surgical procedures (bilateral vagotomy, bladder catheterization, arterial cannulation, phrenic nerve dissection, dorsal transcerebellar access to the ventrolateral medulla oblongata) were standard (Takakura et al., 2006). After surgery, halothane was gradually replaced by urethane $(1.2 \mathrm{~g} / \mathrm{kg}$, administered i.v. over $20 \mathrm{~min})$. This initial dose was supplemented hourly and at least twice with an injection of $0.1 \mathrm{~g} / \mathrm{kg}$. After a total of $1.4-1.5 \mathrm{~g} / \mathrm{kg}$, the level of anesthesia was stable for the rest of the experiment (up to $5 \mathrm{~h}$ after the initial anesthetic crossover). The rats were ventilated with $100 \% \mathrm{O}_{2}$ throughout the experiment and muscle relaxation was performed with pancuronium (initial dose: 1 $\mathrm{mg} / \mathrm{kg}$ i.v.). Rectal temperature was maintained at $37^{\circ} \mathrm{C}$, and end-tidal $\mathrm{CO}_{2}$ was monitored throughout the experiment with a microcapnometer (Columbus Instruments, Columbus, $\mathrm{OH}$ ). The adequacy of anesthesia was continually monitored by testing for lack of arterial pressure (AP) change and lack of change in phrenic nerve discharge (PND) rate or amplitude to firm toe or tail pinch. At the end of the physiological experiment, the rats were deeply anesthetized with halothane (4\% until AP reached $40 \mathrm{mmHg}$ ) and perfused through the left cardiac ventricle with PBS ( $\mathrm{pH} 7.4 ; 150 \mathrm{ml}$ ) followed by paraformaldehyde ( $4 \%$ in $0.1 \mathrm{M}$ phos- phate buffer, $\mathrm{pH} 7.4,500 \mathrm{ml}$ ). The brains were postfixed overnight in the paraformaldehyde solution. The brains were then sectioned in the coronal plane $(30 \mu \mathrm{m})$, and the sections were kept in cryoprotectant awaiting histological procedures.

Arterial blood pressure, $\mathrm{PND}$, tracheal $\mathrm{CO}_{2}$ and tracheal pressure were recorded as previously described (Takakura et al., 2006; Moreira et al., 2007). RTN neurons were characterized as described previously (Mulkey et al., 2004; Takakura et al., 2006; Moreira et al., 2007) except that recordings were made with piggyback iontophoretic electrodes (McCall and Aghajanian, 1979). These electrodes consisted of a recording barrel protruding 25-40 $\mu \mathrm{m}$ from the tip of a five-barrel iontophoretic pipette. One barrel of the iontophoretic electrode contained $4 \mathrm{M} \mathrm{NaCl}$ and was used for automatic current balancing such that the total current delivered by all barrels always equaled zero (McCall and Aghajanian, 1979). Two other barrels contained either serotonin (creatinine sulfate $0.04 \mathrm{M}, \mathrm{pH}$ 4.0, Sigma), substance P (2.75 mm in $20 \mathrm{~mm} \mathrm{Na}$ acetate, $\mathrm{pH}$ 4.5, Sigma) or l-glutamate (monosodium salt, $0.2 \mathrm{M}, \mathrm{pH} 8.0$, Sigma). Serotonin and substance $\mathrm{P}$ were expelled with positive current (total of $80-160 \mathrm{nA}$ delivered from one or two barrels for 5-HT; 60-130 nA for substance P), and glutamate with negative current (100-160 nA). High levels of iontophoretic current were required because of the necessarily large separation between recording and iontophoretic barrels. Attempts to record RTN neurons with other iontophoretic electrode configurations failed. As previously reported, RTN neurons were found between 150 and 300 $\mu \mathrm{m}$ below the lower edge of the facial motor nucleus and from $200 \mu \mathrm{m}$ caudal to $300 \mu \mathrm{m}$ rostral to the caudal boundary of this nucleus (Mulkey et al., 2004; Stornetta et al., 2006; Takakura et al., 2006). This region lies between coronal planes bregma -11.8 and $-11.3 \mathrm{~mm}$ of the Paxinos and Watson (2005). In addition to this specific location, the defining properties of RTN neurons are a strong activation by hypercapnia (discharge threshold at $4-4.5 \% \mathrm{CO}_{2}$ and firing rate of $6-14 \mathrm{~Hz}$ at $10 \% \mathrm{CO}_{2}$ ), a lack of respiratory modulation at low levels of $\mathrm{CO}_{2}$, and a modest respiratory entrainment at high levels of $\mathrm{CO}_{2}$ (Mulkey et al., 2004; Stornetta et al., 2006; Takakura et al., 2006). Before searching for RTN neurons, ventila- 
tion was adjusted to lower end-expiratory $\mathrm{CO}_{2}$ to $4 \%$ at steady-state ( $60-80$ cycles/s; tidal volume $1-1.2 \mathrm{ml} / 100 \mathrm{~g}$ ). Variable amounts of pure $\mathrm{CO}_{2}$ were then added to the breathing mixture to adjust end-expiratory $\mathrm{CO}_{2}$ to the desired level without changing ventilation parameters.

All analog data (end-expiratory $\mathrm{CO}_{2}$, PND, unit activity, $\mathrm{AP}$ ) were stored on a microcomputer via a micro-1401 digitizer from Cambridge Electronics Design (Cambridge, UK) and were processed offline using version 5 of the Spike 2 software (Cambridge Electronics Design) as described previously (Mulkey et al., 2004; Takakura et al., 2006; Moreira et al., 2007). Processing included action potential discrimination and binning and neuronal discharge rate measurement. PND "integration" ( $\left.\int \mathrm{Phr}\right)$ consisted of full-wave rectification and smoothing $(\tau: 0.015 \mathrm{~s})$. The neural equivalent of minute ventilation (mvPND, the product of integrated phrenic amplitude and frequency, $\int \mathrm{Phr} \times f$ ) was determined by averaging $\int \mathrm{Phr}$ during consecutive 1 min periods and subtracting a constant value corresponding to the background recorded at low levels of end-expiratory $\mathrm{CO}_{2}$ (below PND threshold).

Microinjections of serotonin into RTN were done to determine whether activation of the neurons within this structure causes an increase in inspiratory motor outflow. Serotonin was injected by pressure (40-60 psi, $4 \mathrm{~ms}$ pulses, $30 \mathrm{nl}$ in $3-5 \mathrm{~s}$ ) through glass pipettes (20 $\mu \mathrm{m}$ outside diameter) filled with serotonin creatinine sulfate ( $1 \mathrm{~mm}$ in $\mathrm{pH} 7.3$ normal saline with addition of a $1 \%$ dilution of fluorescent microbeads for histological verification of injection sites). The dose of serotonin was chosen by analogy with similar types of experiments performed by Fenik and Veasey (2003). The pipette tip was placed $200 \mu \mathrm{m}$ below the caudal edge of the facial motor nucleus under electrophysiological guidance (for details, see Rosin et al., 2006). Postmortem histological inspection of the location of fluorescent microbeads verified the correct placement of the injections in all cases (results not shown). The broad-spectrum serotonin receptor antagonist methysergide was administered intravenously (1 $\mathrm{mg} / \mathrm{kg})$.

RTN recordings in slices. Details regarding the preparation of brain slices have been described previously (Mulkey et al., 2004). Briefly, neonatal rat (Sprague Dawley) pups of either sex (7-12 d postnatal) were decapitated under ketamine/xylazine anesthesia, and transverse slices $(300 \mu \mathrm{m})$ were prepared from the medullary brainstem in the region of the RTN using a microslicer (DSK 1500E, Dosaka, Kyoto, Japan) in ice-cold substituted Ringer's solution containing the following (in $\mathrm{mm}$ ): 260 sucrose, $3 \mathrm{KCl}, 5 \mathrm{MgCl}_{2}, 1 \mathrm{CaCl}_{2}, 1.25 \mathrm{NaH}_{2} \mathrm{PO}_{4}, 26 \mathrm{NaHCO}_{3}, 10$ glucose, and 1 kynurenic acid. Slices were incubated for $\sim 30 \mathrm{~min}$ at $37^{\circ} \mathrm{C}$ and subsequently at room temperature in normal Ringer's solution (in $\mathrm{mm}): 130 \mathrm{NaCl}, 3 \mathrm{KCl}, 2 \mathrm{MgCl}_{2}, 2 \mathrm{CaCl}_{2}, 1.25 \mathrm{NaH}_{2} \mathrm{PO}_{4}, 26 \mathrm{NaHCO}_{3}$, and 10 glucose. Both substituted and normal Ringer's solutions were bubbled with $95 \% \mathrm{O}_{2} / 5 \% \mathrm{CO}_{2}$. The sex of the pups was not recorded, but RTN neurons with apparently similar properties were identified in the vast majority of the slices.

Electrophysiology. Slices were transferred individually to a recording chamber mounted on a fixed-stage microscope (Zeiss Axioskop FS) and perfused continuously $(\sim 2 \mathrm{ml} / \mathrm{min})$ with a bath solution composed of the following (mM): $140 \mathrm{NaCl}, 3 \mathrm{KCl}, 2 \mathrm{MgCl}_{2}, 2 \mathrm{CaCl}_{2}, 10 \mathrm{HEPES}$, and 10 glucose; the $\mathrm{pH}$ of the bath solution was adjusted between 6.9 and 7.5 by addition of $\mathrm{HCl}$ or $\mathrm{NaOH}$.

The RTN was identified by its location below the caudal end of the facial motor nucleus and individual neurons were visualized using Nomarski optics. Chemosensitive RTN neurons typically had fusiform somas with their long axis parallel to the ventral medulla surface and were typically located within $100 \mu \mathrm{m}$ of the ventral surface (Mulkey et al., 2004).

Recordings were made with an Axopatch 200B patch-clamp amplifier, digitized with a Digidata 1322A analog-to-digital converter, and recorded using pCLAMP 9.0 software (all Molecular Devices, Union City, $\mathrm{CA}$ ). Recordings were obtained at room temperature with patch electrodes pulled from borosilicate glass capillaries (Warner Instruments, Hamden, CT) on a two-stage puller (Sutter Instruments, Novato, CA; P89) to a DC resistance of 3-6 $\mathrm{M} \Omega$ when filled with internal solution containing the following (in $\mathrm{mm}$ ): $120 \mathrm{KCH}_{3} \mathrm{SO}_{3}, 4 \mathrm{NaCl}, 1 \mathrm{MgCl}_{2}, 0.5$ $\mathrm{CaCl}_{2}, 10$ HEPES, 10 EGTA, $3 \mathrm{Mg}-\mathrm{ATP}$, and 0.3 GTP-Tris, pH 7.2;
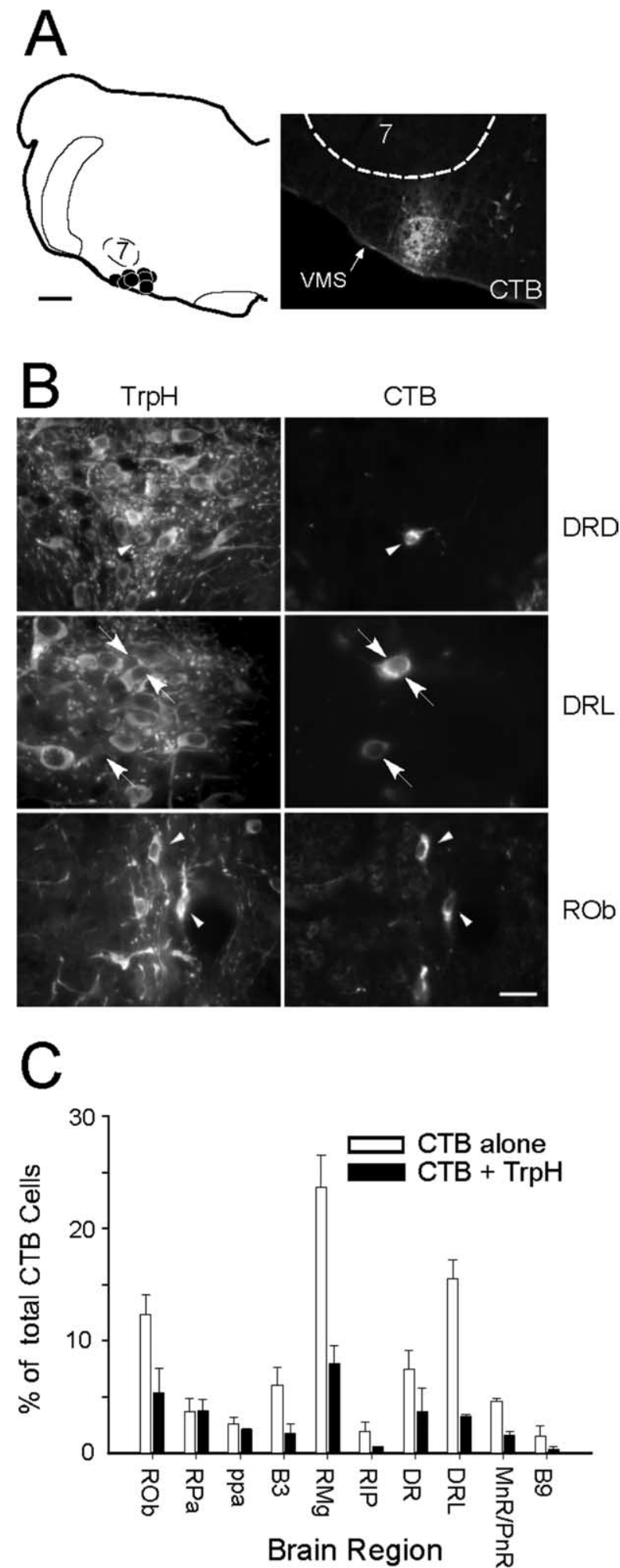

Figure 2. Origin of the serotonergic input to the RTN region. $\boldsymbol{A}$, Left, CTB injection sites ( $n=$ 8). Note that all injections were correctly placed ventral or ventromedial to the caudal end of the facial motor nucleus (7). Right, Representative injection site (CTB immunofluorescence, Cy3). VMS, Ventral medullary surface. $\boldsymbol{B}$, Examples of retrogradely labeled serotonergic neurons (left, TrpH revealed with Alexa 488; right, CTB revealed with (y3) in the dorsal portion of the dorsal raphe nucleus (DRD) and in raphe obscurus (ROb; arrowheads). Arrows point to examples of two CTB-ir cells apparently devoid of TrpH in the lateral portion of DR (DRL). C, Distribution histogram of CTB-ir neurons with or without TrpH that were identified within the various subdivisions of the raphe (average of 3 rats). See supplemental Figure S1 (available at www.jneurosci.org as supplemental material) for definition of counting areas. Scale bars: $\boldsymbol{A}$, left, $500 \mu \mathrm{m}$; (in $\boldsymbol{B}) \boldsymbol{A}$, right, $80 \mu \mathrm{m} ; \boldsymbol{B}$, top and bottom, $20 \mu \mathrm{m} ; \boldsymbol{B}$, middle, $13 \mu \mathrm{m}$. 
electrode tips were coated with Sylgard 184 (Dow Corning, Midland, MI). To determine whether effects of serotonin or substance P on RTN neurons were mediated indirectly, via altered synaptic input, we bath applied the following ionotropic receptor blockers: glutamate receptor antagonists 6-cyano-7-nitroquinoxaline2,3-dione (CNQX, $10 \mu \mathrm{M})$ and 2-amino-5phosphopentanoic acid (APV, $50 \mu \mathrm{M}$ ), glycine receptor antagonist (strychnine, $20 \mu \mathrm{M}$ ), $\mathrm{GABA}_{\mathrm{A}}$ receptor antagonist (bicuculline, $10 \mu \mathrm{M}$ ), and the nonspecific P2 receptor antagonist Reactive Blue 2 (RB2, $50 \mu \mathrm{M})$. Unless otherwise stated, all chemicals were from Sigma. Firing rate histograms from cell-attached recordings were generated by integrating action potential discharge in $10 \mathrm{~s}$ bins and plotted using Spike 5.0 software. Under voltage clamp, cells were recorded in $0.5 \mu \mathrm{M}$ tetrodotoxin (TTX; Alomone Labs, Jerusalem, Israel) at a holding potential of -60 $\mathrm{mV}$. Holding current, resting conductance, and $I-V$ relationships were determined using voltage steps between -40 and $-120 \mathrm{mV}$. Series resistance was typically $<20 \mathrm{M} \Omega$ and was compensated by $65-70 \%$. A liquid junction potential of $10 \mathrm{mV}$ was corrected off-line.

Statistics. Data are reported as means \pm SEM and were analyzed by the paired or unpaired $t$ test as appropriate. Significance was set at a $p$ value of 0.05 .

\section{Results}

\section{The RTN is innervated by nerve} terminals containing serotonin,

\section{substance $P$, or $T R H$}

RTN chemosensitive neurons can be identified histologically by the presence of the transcription factor Phox $2 b$ (Stornetta et al., 2006). These cells are located ventral to the facial motor nucleus with a major concentration at the caudal end of this nucleus. As shown in Figure $1 A$, a fraction of the chemosensitive neurons reside in the marginal layer (a $50 \mu \mathrm{m}$ thick layer of neuropil located below the spinocerebellar tract), and the rest are found mostly within and dorsal to the spinocerebellar tract (dorsal cap of RTN).

Regardless of the location of their somata, the chemosensitive neurons have extensive dendrites both within the marginal layer and in the dorsal cap of RTN (Mulkey et al., 2004). Both of these regions contained a dense network of serotonin-immunoreactive (ir) terminals (Fig. $1 \mathrm{~B}$ ), and the region was also rich in substance $\mathrm{P}$-ir terminals. Within the marginal layer, a large proportion of the substance $\mathrm{P}$-containing terminals were also positive for serotonin (Fig. $1 C$ ), whereas only a few contained the adrenalinesynthesizing enzyme PNMT (Fig. 1D). Thus, the substance P innervation of RTN originates predominantly from serotonergic neurons, but a minor component may derive from adrenergic neurons. A large majority of RTN Phox 2 b-expressing neurons contained levels of neurokinin-1 receptor (NK1R) immunoreactivity that were clearly above background (Fig. $1 E$ ). However, the NK1R immunoreactivity of RTN neurons was generally lighter than that present in the strongly NK1R-ir neurons of the preBötzinger complex (shown in Fig. $1 F$ for comparison). A relatively sparse network of TRH-ir fibers was also identified in RTN (data not shown), but we failed in our attempts to test whether this peptide is also principally colocalized with serotonin in this region.

\section{RTN receives serotonergic innervation from many} raphe nuclei

The source of the serotonergic input to RTN was sought using the retrograde tracer CTB. Small iontophoretic injections of this tracer were placed in RTN $(n=8)$ (Fig. $2 A)$. These injections produced retrograde labeling in many brain areas, as expected (Rosin et al., 2006). Here, we focused on the retrogradely labeled cells that were located in brain areas containing dense concentrations of serotonergic cells (the raphe nuclei). Examples of serotonergic and nonserotonergic retrogradely labeled cells located in the dorsal raphe (midbrain) and in raphe obscurus (medulla oblongata) are illustrated in Figure $2 B$. Overall, $29 \pm 4 \%$ of the CTB-ir cells counted in the various subdivisions of the raphe were serotonergic (total of 1493 CTB-ir cells counted in raphe regions in three rats) (for definition of counting areas, see supplemental Fig. S1, available at www.jneurosci.org as supplemental material). Despite the very small size of the injections, CTB-labeled serotonergic neurons were present in every subdivision of the raphe from the caudal medulla oblongata to the caudal midbrain (raphe obscurus, raphe pallidus, parapyramidal area, B3 and B9 serotonergic cell groups, raphe magnus, raphe interpositus, and pontine, median, and dorsal raphe). The distribution of retrogradely labeled serotonergic neurons within the various raphe subdivisions is shown in Figure $2 C$, and a computer-assisted map of the location of these cells in one rat is shown in Figure 3. In this figure, each panel is a compressed view of all the cells identified in six to eight consecutive sections. Note that many CTB-labeled 


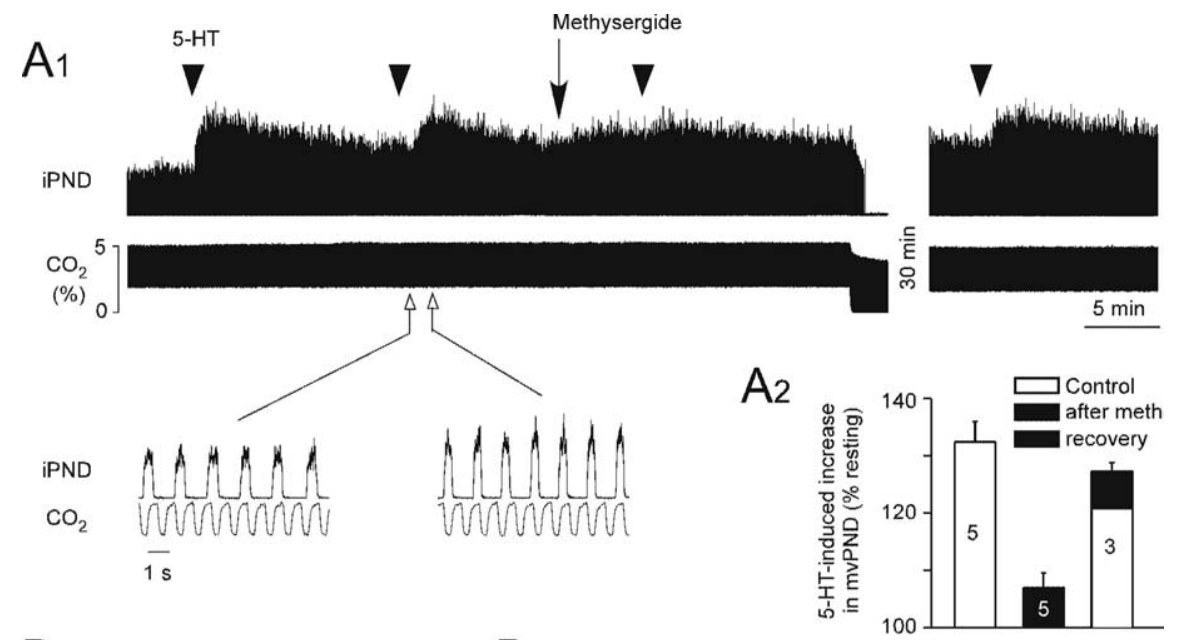

$\mathrm{B}_{1}$
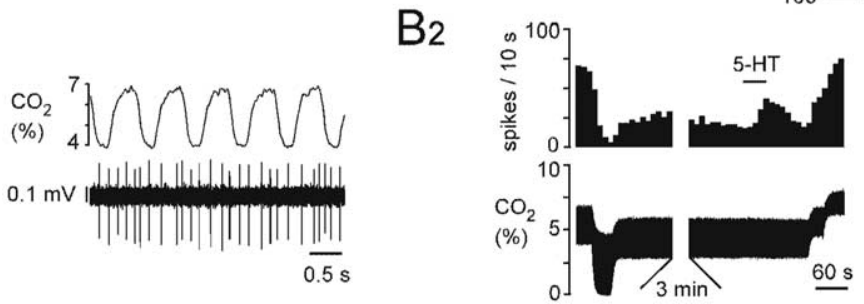

$\mathrm{B}_{3}$
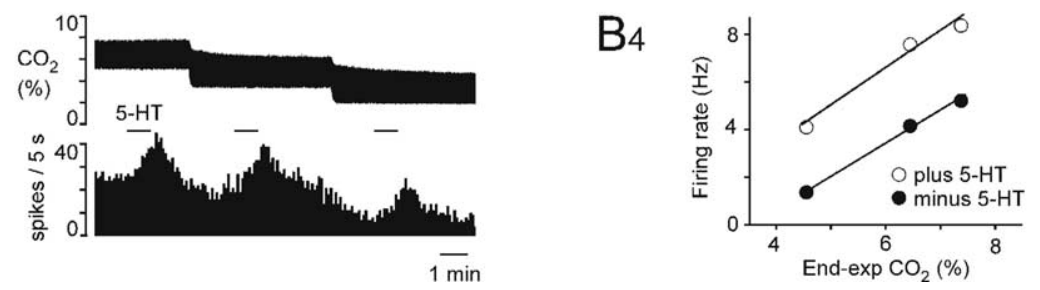

Figure 4. Excitatory effects of serotonin on RTN neurons in vivo. A1, Unilateral injection of 5-HT into RTN (arrowheads) increases the amplitude of PND, and the effect is reversibly attenuated by intravenous injection of the serotonergic antagonist methysergide (arrow; meth). The inset shows on an expanded time scale that injection of 5-HT primarily increased amplitude of PND.A2, Group data showing the effect of serotonin on the product of PND amplitude and frequency (mvPND). The number of rats is indicated within each bar. B1, Typical regular discharge rate of an RTN chemoreceptor. B2, Integrated rate histogram of the unit activity of the cell shown in $B 1$. The left portion of the histogram shows that the cell was silenced by lowering $P C O_{2}$ to $\sim 4.5 \%$. After reincreasing $\mathrm{CO}_{2}$ and cell stabilization (interruption in the histogram), the cell was tested for its response to an iontophoretic application of serotonin. $\boldsymbol{B} 3$, RTN neurons exposed to serotonin ( $85 \mathrm{nA}$, at bars) at three levels of end-expiratory $\mathrm{CO}_{2}$. $\mathbf{B 4}$, Discharge rate of the neuron shown in $\mathbf{B 3}$. The effect of serotonin relative to baseline is the same at the three levels of $\mathrm{CO}_{2}$.

serotonergic neurons were found in regions of the medullary raphe, where serotonergic cells coexpress substance $\mathrm{P}$ and TRH (raphe pallidus, raphe obscurus, parapyramidal, and $\mathrm{B} 3$ region).

\section{Serotonin injection into the RTN in vivo increases inspiratory} motor outflow and activates RTN chemosensitive neurons Unilateral injection of serotonin into RTN increased the amplitude of the phrenic nerve discharge (five rats) (Fig. 4A1). PND frequency was unchanged in four rats and transiently increased by $15 \%$ in one case. The overall effect of these localized unilateral injections of serotonin on mvPND $\left(\int \mathrm{Phr} \times f\right)$ was small $(31 \%$ increase) but repeatable and reproducible between animals (Fig. $4 A 2)$. The effect of the microinjections was attenuated by intravenous administration of the broad-spectrum serotonin receptor antagonist methysergide, indicating that the effect produced by these injections was caused by serotonin as opposed to the vehicle. Recovery from the antagonist was observed in three cases after $>1 \mathrm{~h}$.

Iontophoretic application of serotonin in the vicinity of an RTN chemosensitive neuron was performed in 11 cells from three rats (Fig. 4B). Consistent with prior descriptions, all these cells discharged relatively regularly $\left(5.6 \pm 1 \mathrm{~Hz}\right.$ at a $\mathrm{PCO}_{2}$ of $6.8 \pm 0.6 \%$ ) (example in Fig. $4 B 1$ ), and they displayed a marked sensitivity to $\mathrm{CO}_{2}$ with a discharge threshold $<5 \% \mathrm{CO}_{2}$ (Fig. 4B2-B4). Serotonin increased baseline activity of 10 of $11 \mathrm{CO}_{2}$-sensitive cells $(+2.0 \pm 1.0 \mathrm{~Hz}$ from a baseline of $5.4 \pm 1$ $\mathrm{Hz} ; n=11$; range $0-7.6 \mathrm{~Hz}$ ) (Fig. 4 B2). In five of the cells, serotonin was applied repeatedly and at regular intervals $(3-4 \mathrm{~min})$ while the neuron was exposed to at least two different levels of $\mathrm{CO}_{2}$. As illustrated in Figure $4 B 3, B 4$, the excitatory effect of serotonin (spikes per second over resting level) was very similar regardless of the $\mathrm{CO}_{2}$ level to which the cell was exposed. As a group (five neurons), the effect of serotonin was the same $(p=0.35)$ at low $\mathrm{CO}_{2}$ (5.5 $\pm 0.7 \% \mathrm{CO}_{2} ; 5$-HT-induced increase in firing rate of $3.1 \pm 1.2 \mathrm{~Hz}$ from a resting level of $3.0 \pm 1.2 \mathrm{~Hz})$ as at high $\mathrm{CO}_{2}(7.2 \pm$ $0.7 \%$; 5-HT-induced increase of $3.4 \pm 1.2$ $\mathrm{Hz}$ from a resting level of $5.8 \pm 1.3 \mathrm{~Hz}$ ). In other words, in RTN neurons that are active at rest, serotonin causes an upward resetting of the relationship between discharge rate and $\mathrm{PCO}_{2}$ without change of gain (Fig. 4B4).

Serotonin activates RTN chemosensitive neurons in brain slices by a postsynaptic and $\mathrm{pH}$-independent mechanism

We recorded from RTN chemosensitive neurons in slices to characterize the cellular mechanisms underlying the effects of serotonin. Chemosensitive RTN neurons were identified by their characteristic response to changes in bath $\mathrm{pH}$, i.e., RTN chemoreceptors were spontaneously active under control conditions ( $\mathrm{pH}$ 7.3) became silent during bath alkalization ( $\mathrm{pH} 7.5)$ and increased their firing rate to $>2 \mathrm{~Hz}$ during bath acidification ( $\mathrm{pH}$ 6.9). All neurons included in these studies showed similar responses to changes in extracellular $\mathrm{pH}(\mathrm{pH} 7.3,0.7 \pm 0.1 \mathrm{~Hz}$; $\mathrm{pH} 7.5,0.01 \pm 0.01 \mathrm{~Hz} ; \mathrm{pH} 6.9,2.2 \pm 0.2 \mathrm{~Hz} ; n=19)$. A subset of cells were exposed to a slightly less acidic $\mathrm{pH}$ of 7.0 , which increased activity to $2.2 \pm 0.3 \mathrm{~Hz}(n=5)$, no different from with acidification to $\mathrm{pH} 6.9$, suggesting that RTN chemoreceptors are most sensitive to changes in $\mathrm{pH}$ over a narrow physiological range. The pH sensitivity of the RTN cells included in this study was similar to that found in our previous study (Mulkey et al., 2004).

Chemosensitive RTN neurons responded to bath application of serotonin $(5 \mu \mathrm{M})$ with an increase in firing rate from $1.1 \pm 0.2$ $\mathrm{Hz}$ to $3.1 \pm 0.3 \mathrm{~Hz}(n=27)$. For example, Figure $5 \mathrm{~A} 1$ shows that the firing rate of a $\mathrm{pH}$-sensitive $\mathrm{RTN}$ chemoreceptor is increased by $\sim 1.5 \mathrm{~Hz}$ during exposure to serotonin at $\mathrm{pH}$ 7.3. The excitatory effects of serotonin were presumably direct because they were retained in the presence of a mixture of ionotropic receptor blockers that included glutamate receptor antagonists CNQX (10 $\mu \mathrm{M})$ and $\mathrm{APV}(50 \mu \mathrm{M})$, a glycine receptor antagonist (strychnine, 
$20 \mu \mathrm{M})$, a $\mathrm{GABA}_{\mathrm{A}}$ receptor antagonist (bicuculline, $10 \mu \mathrm{M}$ ), and the nonspecific $\mathrm{P} 2$ receptor antagonist $\mathrm{RB} 2(50 \mu \mathrm{M})$ (Fig. $5 A 1, A 2)$. The excitatory effects of serotonin were blocked by ketanserin $(25 \mu \mathrm{M})$, a $5-\mathrm{HT}_{2 \mathrm{~A}}$-selective receptor antagonist (Fig. $5 A 2, A 3)$. We also assessed $\mathrm{pH}$ sensitivity of RTN chemoreceptors during sustained exposure to serotonin (Fig. 5B1). Serotonin increased the baseline level of RTN discharge, but the magnitude of firing rate response to changes in $\mathrm{pH}$ was similar in the presence and absence of serotonin (Fig. 5B2). Thus, as observed in vivo, serotonin evoked a parallel upward shift in the $\mathrm{pH}$ sensitivity curve of RTN neurons in the slice, suggesting that actions of $\mathrm{pH}$ and serotonin are independent and additive.

We used voltage clamp to test whether serotonin and $\mathrm{pH}$ activate chemosensitive RTN neurons through distinct ionic mechanisms. Figure $6 A 1$ shows an example of the firing rate response of an RTN chemoreceptor to changes in bath $\mathrm{pH}$ and to two successive applications of serotonin in loose patch configuration. In the same neuron under voltage clamp (Fig. 6A2), bath alkalization from $\mathrm{pH} 7.3$ to 7.5 increased outward current at a holding potential of $-60 \mathrm{mV}$, whereas acidification decreased outward current. After returning to control conditions ( $\mathrm{pH}$ 7.3), 5-HT was bath applied twice, and on both occasions it caused a strong inward shift in holding current. We digitally subtracted current responses to incrementing voltage steps under control conditions from those in the presence of 5-HT to obtain an $I-V$ curve for the 5-HT-sensitive current in RTN neurons. As shown in graph of Figure $6 \mathrm{~B}, 5$-HT caused an inward current at all membrane potentials, with little measurable change in conductance. The ionic basis for this current was not explored in detail, but these results suggest that serotonin modulates the activity of multiple ion channels and/or of channels that are electrically remote (i.e., on distal dendrites). In any case, the $I-V$ relationship of the 5-HT-sensitive current was clearly distinct from that of the $\mathrm{pH}$-sensitive background $\mathrm{K}^{+}$ currents in RTN neurons (Mulkey et al., 2004). Further, consistent with the idea that the 5-HT- and $\mathrm{pH}$-sensitive currents are mediated by distinct ionic mechanisms, serotonin had no effect on the amplitude or $I-V$ characteristics of the $\mathrm{pH}$-sensitive current in RTN neurons (Fig. 6C). Together, these results suggest that serotonin does not change the chemoreceptive properties of RTN neurons, even as it increases neuronal excitability.

\section{RTN chemosensitive neurons are activated by substance $P$ or TRH}

Many of the serotonergic neurons located in the medullary raphe also release substance $\mathrm{P}$ and TRH. The next experiments were therefore designed to explore the possibility that these peptides, like serotonin, might also have excitatory effects on RTN chemoreceptors.
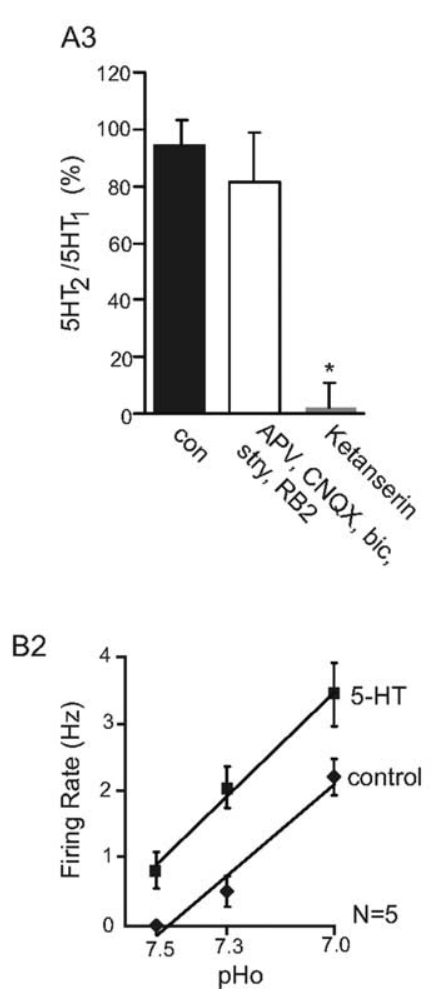

Figure 5. Excitatory effect of serotonin on RTN chemosensitive neurons in vitro. A1, Trace of firing rate and calculated bath $\mathrm{pH}$ and pHo shows the response of another chemosensitive RTN neuron to changes in pHo and exposure to 5-HT. Response to a second application of 5-HT was blocked by bath-applied ketanserin $(25 \mu \mathrm{M})$. The asterisk designates a 5 min time break. A3, Bar (d) response of pH-sensitive RTN neurons to the second of two consecutive applications of 5-HT (data are discharge rate of RTN neurons and $\mathrm{pH}$ in the presence and in the absence of bath-applied 5-HT. The response of the neurons to $\mathrm{pH}$ was unaffected by the presence of serotonin.

Iontophoretic application of substance $\mathrm{P}$ in vivo (100-130 nA for 60-80 s) produced a robust excitation of all RTN chemosensitive neurons tested (from a baseline of $4.4 \pm 0.7 \mathrm{~Hz}$ to $7.5 \pm 0.7$ $\mathrm{Hz} ; p<0.001 ; n=7$ neurons from two rats) (Fig. 7A1,A2). The effect was long lasting (2-3 $\mathrm{min})$ and repeatable. Excitation was observed regardless of the resting level of activity of the neurons, i.e., regardless of the $\mathrm{PCO}_{2}$ level (Fig. 7A1). The delayed onset and slow offset of the response (Fig. 7A1) indicated that the response to current application through the substance P-containing barrels could not have been caused by a current artifact. In addition, delivery of the same amount of positive current through electrode barrels containing glutamate (a substance that requires negative current to be expelled) produced no effect on the discharge of the neurons (result not shown).

Substance $\mathrm{P}$ also produced robust increases in the discharge rate of RTN chemosensitive neurons recorded in slices $(n=11)$ (Fig. 7B1,B2). In six cases (one cell per slice), substance $\mathrm{P}$ was applied in the presence of a mixture of receptor antagonists designed to block purinergic receptors and ionotropic receptors to glutamate, glycine, and GABA. These blockers were applied $5 \mathrm{~min}$ before, during, and after sub- 

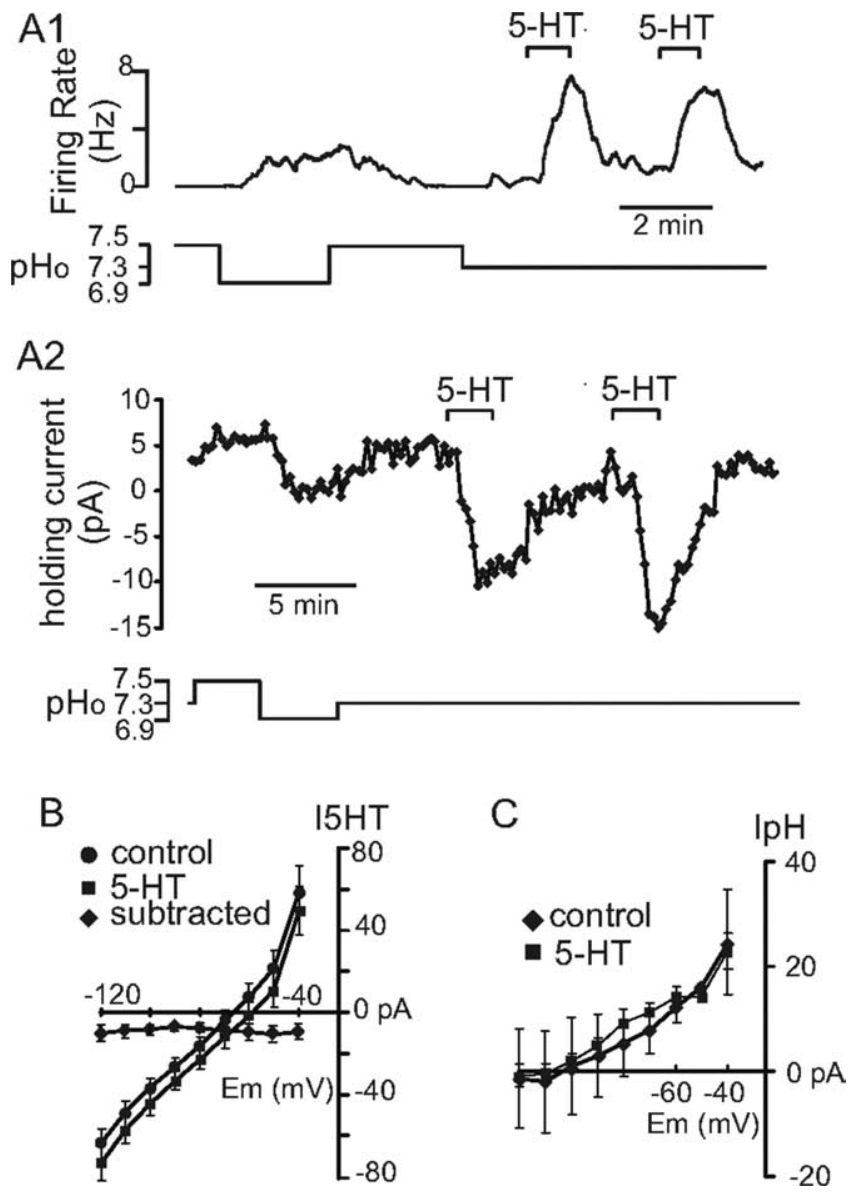

Figure 6. Serotonin and $\mathrm{pH}$ activate chemosensitive RTN neurons through distinct ionic mechanisms. A1, Firing rate trace showing the response of a chemosensitive RTN neuron to 5-HT. A2, Trace of holding current from the same cells as in $\boldsymbol{A} 1$ shows that alkalization evoked an outward current, whereas acidification decreased outward current. Bath application of 5-HT decreased membrane current, and as shown in $I-V$ graph in $B, 5$-HT evoked little change in conductance $(n=10)$. $C$, Average $I-V$ data show that the $\mathrm{pH}$-sensitive current was similar under control conditions and in the presence of 5-HT $(n=3)$.

stance P $(1 \mu \mathrm{M})$. Substance $\mathrm{P}$ was still able to activate the chemosensitive neurons in the presence of these blockers, suggesting that a postsynaptic mechanism is primarily responsible for activation of RTN neurons by this neuropeptide. Finally, bath application of TRH (200 nM) also increased activity of chemosensitive RTN neurons from $0.9 \pm 0.3 \mathrm{~Hz}$ to $3.6 \pm 0.5$ $\mathrm{Hz}$ (Fig. $8 A, B$ ). Furthermore, similar to the response of these cells to serotonin, the effects of TRH also appeared to be independent of $\mathrm{pH}$, because the TRH-induced activation was $\sim 2 \mathrm{~Hz}$ regardless of bath $\mathrm{pH}($ Fig. $8 \mathrm{~B})$.

\section{Discussion}

Here we demonstrate that the RTN region is innervated by multiple groups of serotonergic neurons and that three transmitters elaborated by serotonergic cells located in the lower medulla (substance $\mathrm{P}, \mathrm{TRH}$, and serotonin) have excitatory effects on RTN pH-sensitive neurons. We also show that serotonin produces a parallel upward shift in the relationship between RTN neuron activity and $\mathrm{pH}$, which we attribute to the fact that acidification and serotonin activate these cells by independent and additive mechanisms. The results indicate that serotonergic neurons could activate breathing and the central chemoreflex by stimulating RTN neurons.

\section{Origin of the serotonergic innervation of RTN}

The RTN, recognizable by its defining cluster of Phox2bexpressing neurons near the ventral surface (Stornetta et al., 2006), was found to be richly innervated by serotonergic terminals. This evidence suggests that RTN neurons are in direct synaptic contact with serotonergic terminals. Serotonergic neurons with projections to or through the RTN were detected in every subdivision of the raphe. This result cannot be explained by variations in the site of injection of the retrograde tracer but could be partly attributable to technical reasons. Cholera toxin B can sometimes be picked up by axons of passage even when it is applied by iontophoresis (Chen and Aston-Jones, 1995), and some of the CTB-labeled neurons may simply have had projections through RTN (Gao and Mason, 1997). Also, a proportion of the retrogradely labeled serotonergic neurons may target cells located at the periphery of RTN and/or extend dendrites into this nucleus. Given these experimental limitations, we cannot assert that all the raphe subdivisions in which retrogradely labeled serotonergic neurons were identified actually innervate RTN neurons. However, such heterogeneity of serotonergic input is neither unprecedented nor the rule in the medullary region. A similarly diverse array of serotonergic inputs, including a major projection from raphe dorsalis, converges on the solitary tract nucleus (Schaffar et al., 1988; Gao and Mason, 1997), but the ventral respiratory group, which is richly innervated by medullary serotonergic neurons, lacks input from pontine serotonergic cells (Holtman et al., 1990a).

Because $\mathrm{pH}$-sensitive RTN neurons are located near the ventral surface of the RTN and extend projections along the marginal layer (Mulkey et al., 2004), the presence within this layer of large numbers of serotonergic terminals containing substance $\mathrm{P}$ strongly suggests that these chemosensitive neurons receive at least part of their serotonergic input from raphe pallidus, obscurus, or the parapyramidal area, which are the only raphe subdivisions that express preprotachykinin A (Sasek et al., 1990; Jansen et al., 1995; Li et al., 2005). However, even within these subdivisions of the medullary raphe, retrogradely labeled serotonergic neurons were still very scattered.

The substance P innervation of RTN may also originate from a subset of adrenergic cells in the ventrolateral medulla ( $\mathrm{Li}$ et al., 2005), because a few substance P-ir terminals located in RTN were also immunoreactive for phenyl ethanolamine $N$-methyl transferase. Preprotachykinin is also expressed by brainstem neurons other than serotonergic or catecholaminergic neurons. Many of these nonaminergic neurons are located in regions that innervate the RTN (Li et al., 2005; Rosin et al., 2006) and could be additional sources of substance $\mathrm{P}$ innervation for RTN.

In the brainstem, TRH mRNA is largely, if not exclusively, expressed by serotonergic neurons located in raphe pallidus, raphe obscurus, and the parapyramidal region (Yang et al., 1999). TRH-expressing serotonergic neurons innervate a large fraction of the brainstem and spinal cord, including regions involved in autonomic regulation (Batten, 1995; Jansen et al., 1995; Sun et al., 1995; Talley et al., 2000). These neurons are a plausible source of the TRH innervation of RTN.

\section{Excitatory effects of serotonin, TRH, and substance $\mathrm{P}$ on RTN chemoreceptors}

Microinjection of TRH or substance $\mathrm{P}$ into the $\mathrm{RTN}$ region in vivo causes vigorous stimulation of the respiratory motor outflow (Chen et al., 1990a; Cream et al., 1999). As shown here, serotonin injection into RTN also activates phrenic nerve discharge. Because RTN is near the ventral respiratory group, the respiratory 
stimulation caused by injecting substances into RTN could be partly caused by activation of neurons other than the chemosensitive neurons. However, the result of these injections is consistent with the present observation that serotonin, substance $\mathrm{P}$, and TRH activate identified RTN chemoreceptors. It is also consistent with current understanding of the excitatory role of RTN neurons on breathing (Feldman et al., 2003; Guyenet et al., 2005). In the case of substance $\mathrm{P}$ and serotonin, we could demonstrate that their action had an important postsynaptic component, because RTN neurons express NK1 receptors, the effect of serotonin and substance P on RTN neurons in vitro persisted in the presence of blockers of the most common forms of ionotropic transmission (glutamate GABA, glycine, and ATP), and serotonin produced an inward current in the presence of tetrodotoxin. This evidence does not rule out other, more indirect, effects of serotonin on RTN neurons.

\section{Mechanism of action of serotonin on RTN neurons and expected consequences on breathing and on the central chemoreflex}

Serotonin produced an upward parallel shift of the response of RTN neurons to $\mathrm{CO}_{2} / \mathrm{H}^{+}$. This characteristic, seen both in vivo and in vitro, suggests that serotonin does not modify the cellular mechanisms of $\mathrm{pH}$ detection (chemosensitivity). In support of this interpretation, the inward current produced by acidification is attributable to inhibition of a background $\mathrm{K}^{+}$ conductance (Mulkey et al., 2004) and therefore associated with decreased conductance, whereas the inward current evoked by serotonin was not accompanied by measurable change in conductance. Moreover, the $\mathrm{pH}$-sensitive $\mathrm{K}^{+}$current was unaffected by serotonin.

Given prior evidence that RTN neurons activate respiration (Feldman et al., 2003; Guyenet et al., 2005; Nattie and Li, 2006), the excitatory effect of serotonin on these cells must contribute to the enhancement of breathing caused by increased raphe neuron activity (Hodges et al., 2004a,b; Taylor et al., 2005, 2006; Li et al., 2006). One would also predict that impact of serotonin released within RTN on the central chemoreflex would vary greatly depending on the basal level of activity of the chemosensitive neurons. If a large fraction of these cells were hyperpolarized and silent under resting conditions, a likely premise for nonexercising animals under thermoneutral conditions in which respiratory drive is low, serotonin or raphe stimulation could bring a substantial number of RTN neurons close to their firing threshold. Although this effect might have a minor impact on activity of the formerly silent RTN neurons, it would greatly magnify their subsequent response to a given decrease in $\mathrm{pH}$ and so increase central chemoreflex gain.

B1

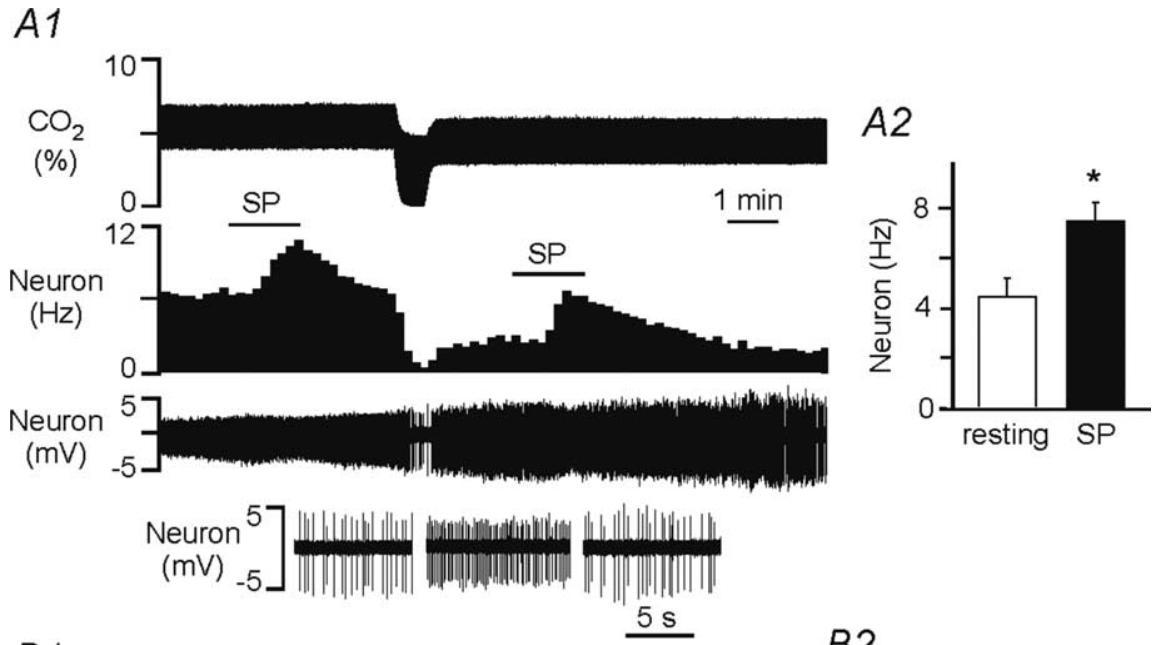

antagonists

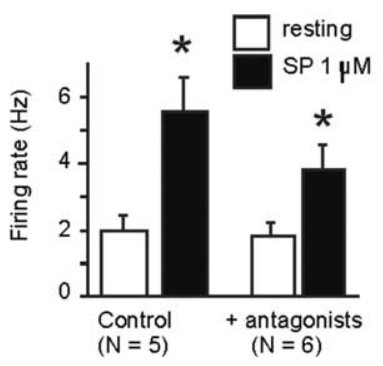

Figure 7. Excitatory effects of substance $P$ on RTN chemosensitive neurons in vivo and in vitro. A1, Effect of iontophoretic applications of substance $P(S P, 130 \mathrm{nA}, 80 \mathrm{~s})$ on the discharge rate of an RTN chemosensitive neuron in vivo. The excitatory effect of $\mathrm{SP}$ was of comparable magnitude under high or low $\mathrm{PCO}_{2}$. The original traces shown at bottom depict the cell before, during and $B 1$, Effect of SP $(1 \mu \mathrm{M})$ on the discharge rate of a representative RTN chemosensitive neuron recorded in a slice in the presence of antagonists of glutamate, glycine, GABA, and purinergic receptors. B2, Effect of SP on the discharge of RTN neurons in the absence

A

Figure 8. Excitatory effects of TRH on RTN chemosensitive neurons in vitro. $\boldsymbol{A}$, Effect of $200 \mathrm{~nm}$ TRH on a representative RTN chemosensitive neuron recorded in cell-attached mode in a slice. $\boldsymbol{B}$, Average effect of TRH was independent of $\mathrm{pH} 0$; TRH increased firing rate by $2.0 \pm 0.3 \mathrm{~Hz}(n=5), 2.7 \pm 0.4 \mathrm{~Hz}(n=5)$, and $2.0 \pm 0.5(n=7)$ at pHo values of 7.5, 7.3, and 6.9, respectively.
This predicted effect is consistent with the enhancement of the chemoreflex gain seen during raphe stimulation in resting animals and the gain reduction observed in animals in which serotonergic neurons are damaged, missing, or inhibited (Hodges et al., 2004a,b, 2007; Taylor et al., 2005, 2006; Li et al., 2006; Dias et al., 2007).

\section{Functional significance}

The overall function of serotonergic neurons is still unclear, but one could make the case that subsets of serotonergic neurons discharge in a manner that tracks the level of activity of specific major organ groups (e.g., skeletomotor system, thermogenic organs, brain at large in the case of the dorsal raphe, etc.) (Lovick, 1997; Jacobs et al., 2002). For example, raphe pallidus and para- 
pyramidal serotonergic neurons contribute to the regulation of thermogenesis by activating brown fat and by causing cutaneous vasoconstriction and shivering (Morrison, 2004; Nakamura et al., 2004; Tanaka et al., 2006). The upregulation of RTN by such serotonergic neurons may serve to activate breathing when $\mathrm{CO}_{2}$ production increases as a result of shivering muscles or brown fat thermogenesis. Such a mechanism could be viewed as a form of central command, a term used to describe a centrally generated adjustment of the cardiorespiratory motor outflow that maintains blood gas homeostasis while minimizing the need for error correction by chemoreceptors and other feedback mechanisms (Waldrop et al., 2006). The concept can be extended to the other serotonergic cell groups. For example, most raphe obscurus neurons presumed to be serotonergic appear to track the intensity of physical exercise (Jacobs and Fornal, 1997). During exercise, these neurons may stimulate breathing by activating RTN, thereby contributing to $\mathrm{PCO}_{2}$ homeostasis (Li et al., 2006). In addition, some medullary and dorsal raphe neurons are activated by hypercapnia in vivo (Veasey et al., 1995), which could increase activity of multiple components of the respiratory system as well as increase responsiveness of RTN neurons to $\mathrm{CO}_{2}$, thereby contributing to the exquisite sensitivity of the respiratory outflow to pH (Richerson et al., 2005). Pontine and medullary serotonergic neurons have a state-dependent level of activity characterized by a much higher level of discharge during waking than during sleep (Veasey et al., 1995, 1997). During waking and at normal $\mathrm{CO}_{2}$ levels, serotonergic input to RTN neurons could make a greater contribution to the ongoing activity of RTN neurons than $\mathrm{CO}_{2}$ itself. Such an effect could contribute to the so-called awake respiratory drive, a term alluding to the fact that breathing while awake persists even at very low $\mathrm{CO}_{2}$ levels. Finally, the dorsal raphe has also been implicated in stress and anxiety responses (Abrams et al., 2005), so conceivably projections from these cells to RTN contribute to the increased ventilation associated with these conditions.

In brief, via their projections to RTN and other components of the breathing network such as the ventral respiratory group and phrenic motor neurons (Holtman et al., 1986, 1990a,b), serotonergic neurons may contribute to matching breathing intensity to the overall metabolic rate.

\section{References}

Abrams JK, Johnson PL, Hay-Schmidt A, Mikkelsen JD, Shekhar A, Lowry CA (2005) Serotonergic systems associated with arousal and vigilance behaviors following administration of anxiogenic drugs. Neuroscience 133:983-997.

Alheid GF, Gray PA, Jiang MC, Feldman JL, McCrimmon DR (2002) Parvalbumin in respiratory neurons of the ventrolateral medulla of the adult rat. J Neurocytol 31:693-717.

Batten TFC (1995) Immunolocalization of putative neurotransmitters innervating autonomic regulating neurones of cat ventral medulla. Brain Res Bull 37:487-506.

Bohn MC, Dreyfus CF, Friedman WJ, Markey KA (1987) Glucocorticoid effects on phenylethanolamine N-methyltransferase (PNMT) in explants of embryonic rat medulla oblongata. Brain Res 465:257-266.

Bonham AC (1995) Neurotransmitters in the CNS control of breathing. Respir Physiol 101:219-230.

Bradley SR, Pieribone VA, Wang WG, Severson CA, Jacobs RA, Richerson GB (2002) Chemosensitive serotonergic neurons are closely associated with large medullary arteries. Nat Neurosci 5:401-402.

Chen S, Aston-Jones G (1995) Evidence that cholera toxin B subunit (CTb) can be avidly taken up and transported by fibers of passage. Brain Res 674:107-111.

Chen Z, Hedner J, Hedner T (1990a) Local effects of substance P on respiratory regulation in the rat medulla oblongata. J Appl Physiol 68:693-699.

Chen Z, Hedner J, Hedner T (1990b) Substance P in the ventrolateral me- dulla oblongata regulates ventilatory responses. J Appl Physiol 68:2631-2639.

Cream C, Nattie E, Li A (1999) TRH microdialysis into the RTN of the conscious rat increases breathing, metabolism, and temperature. J Appl Physiol 87:673-682.

Dias MB, Nucci TB, Margatho LO, Antunes-Rodrigues J, Gargaglioni LH, Branco LG (2007) Raphe magnus nucleus is involved in ventilatory but not hypothermic response to $\mathrm{CO}_{2}$. J Appl Physiol 103:1780-1788.

Feldman JL, Mitchell GS, Nattie EE (2003) Breathing: rhythmicity, plasticity, chemosensitivity. Annu Rev Neurosci 26:239-266.

Fenik P, Veasey SC (2003) Pharmacological characterization of serotonergic receptor activity in the hypoglossal nucleus. Am J Respir Crit Care Med 167:563-569.

Gao KM, Mason P (1997) Somatodendritic and axonal anatomy of intracellularly labeled serotonergic neurons in the rat medulla. J Comp Neurol 389:309-328.

Guyenet PG, Sevigny CP, Weston MC, Stornetta RL (2002) Neurokinin-1 receptor-expressing cells of the ventral respiratory group are functionally heterogeneous and predominantly glutamatergic. J Neurosci 22:3806-3816.

Guyenet PG, Stornetta RL, Bayliss DA, Mulkey DK (2005) Retrotrapezoid nucleus: a litmus test for the identification of central chemoreceptors. Exp Physiol 90:247-253.

Hodges MR, Martino P, Davis S, Opansky C, Pan LG, Forster HV (2004a) Effects on breathing of focal acidosis at multiple medullary raphe sites in awake goats. J Appl Physiol 97:2303-2309.

Hodges MR, Opansky C, Qian B, Davis S, Bonis J, Bastasic J, Leekley T, Pan LG, Forster HV (2004b) Transient attenuation of CO2 sensitivity after neurotoxic lesions in the medullary raphe area of awake goats. J Appl Physiol 97:2236-2247.

Hodges MR, Wang W, Chen ZF, Deneris ES, Johnson RL, Richerson GB (2007) Adult mice with genetic deletion of 5-HT neurons exhibit a severe loss of central chemoreception. FASEB J Abstr 21:1b569.

Holtman Jr JR, Dick TE, Berger AJ (1986) Involvement of serotonin in the excitation of phrenic motoneurons evoked by stimulation of the raphe obscurus. J Neurosci 6:1185-1193.

Holtman Jr JR, Marion LJ, Speck DF (1990a) Origin of serotonincontaining projections to the ventral respiratory group in the rat. Neuroscience 37:541-552.

Holtman Jr JR, Vascik DS, Maley BE (1990b) Ultrastructural evidence for serotonin-immunoreactive terminals contacting phrenic motoneurons in the cat. Exp Neurol 109:269-272.

Jacobs BL, Fornal CA (1997) Serotonin and motor activity. Curr Opin Neurobiol 7:820-825.

Jacobs BL, Martín-Cora FJ, Fornal CA (2002) Activity of medullary serotonergic neurons in freely moving animals. Brain Res Rev 40:45-52.

Jansen ASP, Wessendorf MW, Loewy AD (1995) Transneuronal labeling of CNS neuropeptide and monoamine neurons after pseudorabies virus injections into the stellate ganglion. Brain Res 683:1-24.

Li A, Zhou S, Nattie E (2006) Simultaneous inhibition of caudal medullary raphe and retrotrapezoid nucleus decreases breathing and the $\mathrm{CO} 2$ response in conscious rats. J Physiol (Lond) 577:307-318.

Li Q, Goodchild AK, Seyedabadi M, Pilowsky PM (2005) Pre-protachykinin A mRNA is colocalized with tyrosine hydroxylase-immunoreactivity in bulbospinal neurons. Neuroscience 136:205-216.

Lindsay AD, Feldman JL (1993) Modulation of respiratory activity of neonatal rat phrenic motoneurones by serotonin. J Physiol (Lond) 461:213-234.

Lovick TA (1997) The medullary raphe nuclei: a system for integration and gain control in autonomic and somatomotor responsiveness? Exp Physiol 82:31-41.

Manzke T, Guenther U, Ponimaskin EG, Haller M, Dutschmann M, Schwarzacher S, Richter DW (2003) 5-HT4(a) receptors avert opioid-induced breathing depression without loss of analgesia. Science 301:226-229.

McCall RB, Aghajanian GK (1979) Serotonergic facilitation of facial motoneuron excitation. Brain Res 169:11-27.

Moreira TS, Takakura AC, Colombari E, West GH, Guyenet PG (2007) Inhibitory input from slowly adapting lung stretch receptors to retrotrapezoid nucleus chemoreceptors. J Physiol (Lond) 580:285-300.

Morrison SF (2004) Central pathways controlling brown adipose tissue thermogenesis. News Physiol Sci 19:67-74.

Mulkey DK, Stornetta RL, Weston MC, Simmons JR, Parker A, Bayliss DA, 
Guyenet PG (2004) Respiratory control by ventral surface chemoreceptor neurons in rats. Nat Neurosci 7:1360-1369.

Nakamura K, Matsumura K, Hubschle T, Nakamura Y, Hioki H, Fujiyama F, Boldogkoi Z, Konig M, Thiel HJ, Gerstberger R, Kobayashi S, Kaneko T (2004) Identification of sympathetic premotor neurons in medullary raphe regions mediating fever and other thermoregulatory functions. J Neurosci 24:5370-5380.

Nakaya Y, Kaneko T, Shigemoto R, Nakanishi S, Mizuno N (1994) Immunohistochemical localization of substance P receptor in the central nervous system of the adult rat. J Comp Neurol 347:249-274.

Nattie E, Li A (2006) Central chemoreception 2005: a brief review. Auton Neurosci 126-127:332-338.

Nattie EE, Fung ML, Li A, St John WM (1993) Responses of respiratory modulated and tonic units in the retrotrapezoid nucleus to CO2. Respir Physiol 94:35-50.

Pattyn A, Morin X, Cremer H, Goridis C, Brunet JF (1997) Expression and interactions of the two closely related homeobox genes Phox $2 \mathrm{a}$ and Phox2b during neurogenesis. Development 124:4065-4075.

Paxinos G, Watson C (2005) The rat brain in stereotaxic coordinates, Ed 5. San Diego: Academic.

Richerson GB (2004) Serotonergic neurons as carbon dioxide sensors that maintain ph homeostasis. Nat Rev Neurosci 5:449-461.

Richerson GB, Wang W, Hodges MR, Dohle CI, Diez-Sampedro A (2005) Homing in on the specific phenotype(s) of central respiratory chemoreceptors. Exp Physiol 90:259-266.

Richter DW, Manzke T, Wilken B, Ponimaskin E (2003) Serotonin receptors: guardians of stable breathing. Trends Mol Med 9:542-548.

Rosin DL, Zeng D, Stornetta RL, Norton FR, Riley T, Okusa MD, Guyenet PG, Lynch KR (1993) Immunohistochemical localization of alpha 2Aadrenergic receptors in catecholaminergic and other brainstem neurons in the rat. Neuroscience 56:139-155.

Rosin DL, Weston MC, Sevigny CP, Stornetta RL, Guyenet PG (2003) Hypothalamic orexin (hypocretin) neurons express vesicular glutamate transporters VGLUT1 or VGLUT2. J Comp Neurol 465:593-603.

Rosin DL, Chang DA, Guyenet PG (2006) Afferent and efferent connections of the rat retrotrapezoid nucleus. J Comp Neurol 499:64-89.

Sasek CA, Wessendorf MW, Helke CJ (1990) Evidence for co-existence of thyrotropin-releasing hormone, substance $\mathrm{P}$ and serotonin in ventral medullary neurons that project to the intermediolateral cell column in the rat. Neuroscience 35:105-119.

Schaffar N, Kessler JP, Bosler O, Jean A (1988) Central serotonergic projections to the nucleus tractus solitarii: evidence from a double labeling study in the rat. Neuroscience 26:951-958.
Schwarzacher SW, Pestean A, Günther S, Ballanyi K (2002) Serotonergic modulation of respiratory motoneurons and interneurons in brainstem slices of perinatal rats. Neuroscience 115:1247-1259.

Severson CA, Wang W, Pieribone VA, Dohle CI, Richerson GB (2003) Midbrain serotonergic neurons are central $\mathrm{pH}$ chemoreceptors. Nat Neurosci 6:1139-1140.

Stornetta RL, Moreira TS, Takakura AC, Kang BJ, Chang DA, West GH, Brunet JF, Mulkey DK, Bayliss DA, Guyenet PG (2006) Selective expression of Phox $2 \mathrm{~b}$ by brainstem neurons involved in chemosensory integration in the adult rat. J Neurosci 26:10305-10314.

Sun QJ, Pilowsky P, Llewellyn-Smith IJ (1995) Thyrotropin-releasing hormone inputs are preferentially directed towards respiratory motoneurons in rat nucleus ambiguus. J Comp Neurol 362:320-330.

Takakura AC, Moreira TS, Colombari E, West GH, Stornetta RL, Guyenet PG (2006) Peripheral chemoreceptor inputs to retrotrapezoid nucleus (RTN) CO2-sensitive neurons in rats. J Physiol (Lond) 572:503-523.

Talley EM, Lei QB, Sirois JE, Bayliss DA (2000) TASK-1, a two-pore domain $\mathrm{K}^{+}$channel, is modulated by multiple neurotransmitters in motoneurons. Neuron 25:399-410.

Tanaka M, Owens NC, Nagashima K, Kanosue K, McAllen RM (2006) Reflex activation of rat fusimotor neurons by body surface cooling, and its dependence on the medullary raphe. J Physiol (Lond) 572:569-583.

Taylor NC, Li A, Nattie EE (2005) Medullary serotonergic neurones modulate the ventilatory response to hypercapnia, but not hypoxia in conscious rats. J Physiol (Lond) 566:543-557.

Taylor NC, Li A, Nattie EE (2006) Ventilatory effects of muscimol microdialysis into the rostral medullary raphe region of conscious rats. Respir Physiol Neurobiol 153:203-216.

Veasey SC, Fornal CA, Metzler CW, Jacobs BL (1995) Response of serotonergic caudal raphe neurons in relation to specific motor activities in freely moving cats. J Neurosci 15:5346-5359.

Veasey SC, Fornal CA, Metzler CW, Jacobs BL (1997) Single-unit responses of serotonergic dorsal raphe neurons to specific motor challenges in freely moving cats. Neuroscience 79:161-169.

Waldrop TG, Iwamoto GA, Haouzi P (2006) Point:Counterpoint: Supraspinal locomotor centers do/do not contribute significantly to the hyperpnea of dynamic exercise. J Appl Physiol 100:1077-1083.

Wang H, Stornetta RL, Rosin DL, Guyenet PG (2001) Neurokinin-1 receptor-immunoreactive neurons of the ventral respiratory group in the rat. J Comp Neurol 434:128-146.

Yang H, Yuan P, Wu V, Tache Y (1999) Feedback regulation of thyrotropinreleasing hormone gene expression by thyroid hormone in the caudal raphe nuclei in rats. Endocrinology 140:43-49. 